\title{
Seed Train Process Intensification Strategy Offers Potential for Rapid, Cost-Effective Scale-Up of Biosimilars Manufacturing
}

\author{
By Rajib Malla, Dhaval D. Shah, Chinmay Gajendragadkar, Vijayalakshmi Vamanan, Deepak Singh,
} Suraj Gupta, Deepak Vengovan, Ravi Trivedi, Henry Weichert, Melisa Carpio, and Krishna Chandran

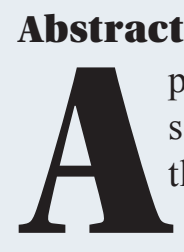

perfusion approach at $\mathrm{N}-1$, where cells stay in the exponential growth phase throughout the entire culture duration, is becoming more common as a strategy for process intensification. This is because the higher cell densities it generates allows manufacturers to skip seed stages and reduce process transfer time through multiple bioreactor sizes, thus providing more cost-effective biologics production in smaller facilities. However, this N-1 perfusion approach requires optimization. In this article, we describe the development and proof-of-concept studies with single-use rocking motion perfusion bioreactors in which we have achieved a ten-fold increase in viable cell count in $\mathrm{N}-1$ seed stage, compared to the fed-batch control process, in just $6-8$ days. We also mention in detail how we inoculated a $50 \mathrm{~L}$ bioreactor production run using this intensified seed train and show comparable growth kinetics and yield with a control process, also at $50 \mathrm{~L}$ scale. Using this intensification approach in the future will help our manufacturing facility, the Biopharma Division of Intas Pharmaceuticals Ltd., reach 4000 L production-scale volumes with fewer process transfer steps, and without changing the feeding strategy or production bioreactors of our biologics' portfolio.

\section{Introduction}

The current costs and global accessibility of biologics and vaccines requires the biopharmaceutical industry to pursue rapid, yet economic development strategies. One approach for shortening manufacturing timelines and reducing the cost of goods is "process intensification." This strategy was originally pioneered in the United Kingdom by the process technology group at Imperial Chemical Industries (ICI) to reduce their plant size, capital investments, and overhead costs while increasing productivity. ${ }^{[1]}$

Today, upstream and downstream bioprocess intensification can be achieved in smaller facilities with fewer scale-up steps to rapidly produce large numbers of therapeutic doses. An intensified cell culture process could improve overall manufacturing yields to enable the use of smaller-volume bioreactors. For example, by increasing the final cell titer by $1 \log$, a potential scale-up could be reduced from $20,000 \mathrm{~L}$ to $2000 \mathrm{~L}$. This would significantly impact facility footprints, production timelines, media, buffer, reagent, and plant utility costs, as well as allowing the transition from large stainless steel vessels to smaller, more cost-efficient single-use (SU) bioreactors.

One area where upstream bioprocessing can be intensified is in the seed train. This article discusses how SU rocking motion (RM) and stirred tank bioreactor technology is being integrated and tested at leading biosimilars product manufacturer, Intas Biopharmaceuticals Ltd., Biopharma Division (Intas), to develop an intensified cell culture seed train protocol.

Traditionally, the seed train for production of a biosimilar at Intas has five transfer stages (Figure 1) beginning with using shake flasks in the post-thaw expansion (N-4) and then moving through a $5 \mathrm{~L}$ rocking motion bioreactor (N-3) to seed $50 \mathrm{~L}$ and $500 \mathrm{~L}$ stirred tank bioreactors (N-2 and $\mathrm{N}-1$ ) and ending in a production culture with a final volume of $4000 \mathrm{~L}(\mathrm{~N})$. The perfusion approach at N-1 is being adopted by several major biopharma companies, including Bristol-Myers Squibb ${ }^{[2-4]}$ and Roche ${ }^{[5]}$, where cells stay in the exponential growth phase throughout the entire culture. Intas has performed a series of studies with SU RM perfusion bioreactors (working volume $25 \mathrm{~L}$ ). The goal was to achieve at least $50 \times 10^{6} / \mathrm{mL}$ viable cell concentration (VCC) and $>95 \%$ cell viability for seeding the production-scale main bioreactor (4000 L) at a higher initial VCC. 

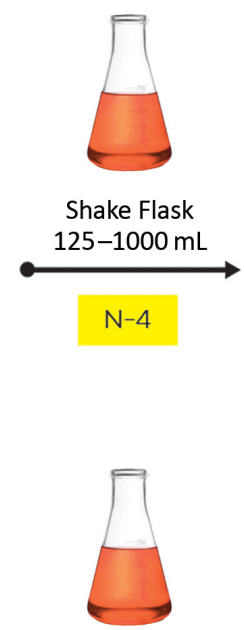

Shake Flask $\stackrel{125-1000 \mathrm{~mL}}{\longrightarrow}$ $\mathrm{N}-2$

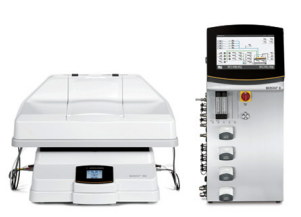

Biostat $^{\circledR}$ RM Bioreactor

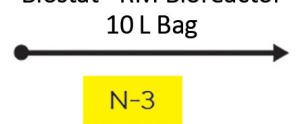

$\mathrm{N}-3$
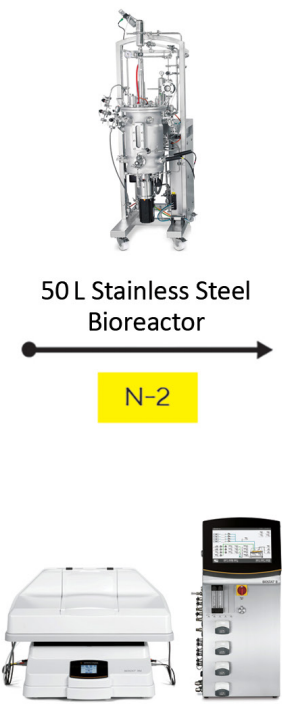

Biostat ${ }^{\circledR}$ RM Bioreactor 50 L Perfusion Bag

$\mathrm{N}-1$
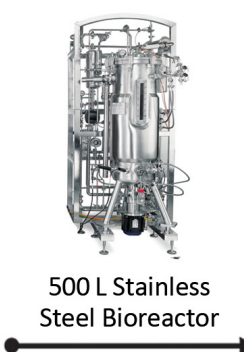

$\mathrm{N}-1$

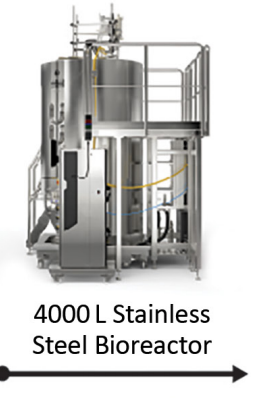

N

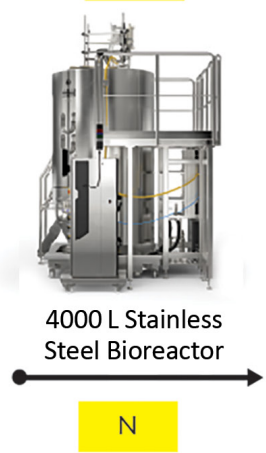

FIGURE 1. Traditional fed-batch (top) and perfusion (below) seed train cell culture process workflow.

\section{Materials and Methods}

\section{Cell Line}

A CHO-S cell line expressing a therapeutic monoclonal antibody $(\mathrm{mAb})$, which is used as a commercial biosimilar, was chosen for the study. This cell line, its associated (proprietary) media, and culture parameters were selected for proof-of-concept experiments because the process has been well-characterized by Intas. Using this clone and media in an established 6-7 day fed-batch culture process that produces a $50-70 \times 10^{6} / \mathrm{mL}$ VCC served as the benchmark which Intas scientists aimed for when adding perfusion culture into the seed train.

\section{Bioreactors}

The Biostat ${ }^{\circledR}$ RM 20/50 (Sartorius) was selected for the seed train studies because it is a fully GMP-compliant, rocking motion system where the surface of the medium is continuously renewed. This allows mass transfer between the headspace and medium for efficient mixing with low shear. SU Flexsafe ${ }^{\circledR}$ RM and stirred-tank (STR) bags (Sartorius) were used throughout the entire study. They are constructed of pharmaceutical-grade, low-density polyethylene with proven cell growth properties as the contact layer. ${ }^{[6]}$ The Flexsafe RM perfusion bag features an integrated membrane at the bottom for cell-free removal of media during the culture process, with minimal cell loss or damage. Studies have shown that RM perfusion bioreactors can produce very high cell densities $\left(\geq 40-100 \times 10^{6} / \mathrm{mL}\right)$ at scales up to $25 \mathrm{~L}$ working volume. ${ }^{[7,8]}$ This makes it possible to produce cells with high enough densities and viabilities to directly seed a production bioreactor. Additionally, the Biostat family of RM bioreactors scale from 10-100 L working volume, making process transfer simpler.

A Biostat STR 50 L bioreactor with SU Flexsafe STR bags was used in the pilot scale studies. This bioreactor comes in scales from 50-2000 L. A 4000 L stainless steel system served as the production bioreactor. The SU bioreactors uses the same established bioreactor design principles as the $4000 \mathrm{~L}$ stainless steel bioreactor, and all the STR bags have similar geometries across scales ${ }^{[9]}$, which simplifies process transfer and scale-up. ${ }^{[10]}$

\section{Trial Batches}

Five seed train trial batch studies were performed to determine the optimum parameters for process intensification. CHO-S cells were cultured in shake flasks $(125-500 \mathrm{~mL}$ volume) and used to seed growth media $(5 \mathrm{~L})$ in $10 \mathrm{~L} \mathrm{SU}$ bags on the RM 20/50 bioreactor using a range of conditions (Table 1), media volumes, and inoculation densities (Table 2). Cells were sampled manually for analysis via the bioreactor bag's Luer connection using a sterile SU syringe. When the VCC reached $>2.0-2.5 \times 10^{6} / \mathrm{mL}$, perfusion culture was started by continuous feeding and harvesting from a feed and harvest vessel (Table 3) until the minimum target VCC of $>50 \times 10^{6} / \mathrm{mL}$ was reached. VCC, cell viability, metabolites, glucose, and lactate were measured daily (where practicable) and used as performance indicators. 


\section{Proof-of-Concept Development}

Cells cultured in the RM bioreactor (N-1) from batches 3 and 4 were used to seed two $50 \mathrm{~L}$ pilot batches (runs 1 and 2) in separate SU STR bioreactors. They were operated using different stir speeds, feed, and media to define the best culture parameters and yields.

\section{Confirmation Run}

After the intensification process was optimized at the N-1 perfusion stage, an additional confirmation run (batch 5) was carried out in the RM bioreactor for inoculation into a 50 L STR bioreactor (run 3). The culture performance of cells in the 50 L STR were compared with cells cultured in a control-seeded 50 L STR batch (inoculated using cells from a standard fed-batch culture). This served as a proofof-concept to show how cells cultured using perfusion for process intensification performed against the traditional fed-batch seed train expansion methods.

\begin{tabular}{|l|c|c|c|c|c|}
\hline \multicolumn{7}{|c|}{ TABLE 1. CHO-S cell culture conditions. } \\
\hline \multicolumn{1}{|c|}{ Parameters } & Batch 1 & Batch 2 & Batch 3 & Batch 4 & Batch 5 \\
\hline Inoculum VCC & $0.5 \times 10^{6} / \mathrm{mL}$ & $0.5 \times 10^{6} / \mathrm{mL}$ & $0.5 \times 10^{6} / \mathrm{mL}$ & $0.5 \times 10^{6} / \mathrm{mL}$ & $0.5 \times 10^{6} / \mathrm{mL}$ \\
\hline Inoculum cell viability & $99 \%$ & $99 \%$ & $99 \%$ & $99 \%$ & $99 \%$ \\
\hline pH post-inoculation & 7.29 & 7.14 & 7.22 & 7.25 & 7.20 \\
\hline pH setpoint & 7.00 & 7.00 & 7.00 & 7.00 & 7.00 \\
\hline Temperature & $37^{\circ} \mathrm{C}$ & $37^{\circ} \mathrm{C}$ & $37^{\circ} \mathrm{C}$ & $37^{\circ} \mathrm{C}$ & $37^{\circ} \mathrm{C}$ \\
\hline Initial DO & $40^{\circ}$ & $40 \%$ & $40 \%$ & $40 \%$ & $40 \%$ \\
\hline $\begin{array}{l}\text { Initial rocker speed } \\
\text { (RPM) }\end{array}$ & 16 & 16 & 16 & 16 & 16 \\
\hline Initial rocker angle & $6^{\circ}$ & $6^{\circ}$ & $6^{\circ}$ & 6.1 & $6^{\circ}$ \\
\hline $\begin{array}{l}\text { Initial aeration flow rate } \\
\text { O2 (LPM) }\end{array}$ & 0.1 & 0.1 & 0.1 & 0.1 & 0.1 \\
\hline Final rocker speed (RPM) & 22 & 22 & 23 & 23 & 23 \\
\hline Final rocker angle & $10^{\circ}$ & $9^{\circ}$ & $9^{\circ}$ & $10^{\circ}$ & $10^{\circ}$ \\
\hline $\begin{array}{l}\text { Final aeration flow rate } \\
\text { O2 (LPM) }\end{array}$ & 0.2 & 0.3 & 0.4 & 0.7 & 0.5 \\
\hline \multicolumn{1}{|c|}{ NOTE: Dissolved oxygen (DO), revolutions per minute (RPM), and liters per minute (LPM) } \\
\hline
\end{tabular}

\begin{tabular}{|c|c|c|c|c|c|}
\hline Parameters & Batch 1 & Batch 2 & Batch 3 & Batch 4 & Batch 5 \\
\hline Initial media volume & $3.7 \mathrm{~L}$ & $3.5 \mathrm{~L}$ & $3.62 \mathrm{~L}$ & $3.7 \mathrm{~L}$ & $3.6 \mathrm{~L}$ \\
\hline Inoculum volume & $216 \mathrm{~mL}$ & $200 \mathrm{~mL}$ & $271 \mathrm{~mL}$ & $300 \mathrm{~mL}$ & $350 \mathrm{~mL}$ \\
\hline $\begin{array}{l}\text { Bioreactor volume } \\
\text { post-inoculation }\end{array}$ & $4.0 \mathrm{~L}$ & $3.7 \mathrm{~L}$ & $3.9 \mathrm{~L}$ & $4.0 \mathrm{~L}$ & $4.0 \mathrm{~L}$ \\
\hline VCC post-inoculation (at $0 \mathrm{~h}$ ) & $0.59 \times 10^{6} / \mathrm{mL}$ & $0.45 \times 10^{6} / \mathrm{mL}$ & $0.45 \times 10^{6} / \mathrm{mL}$ & $0.49 \times 10^{6} / \mathrm{mL}$ & $0.48 \times 10^{6} / \mathrm{mL}$ \\
\hline $\begin{array}{l}\text { Cell viability post-inoculation } \\
(0 \mathrm{~h})\end{array}$ & $99.0 \%$ & $99.5 \%$ & $99.5 \%$ & $99.5 \%$ & $99.2 \%$ \\
\hline Batch duration (days) & 6 & 10 & 9 & 8 & 6 \\
\hline VCC at harvest & $14.5 \times 10^{6} / \mathrm{mL}$ & $50 \times 10^{6} / \mathrm{mL}$ & $88.5 \times 10^{6} / \mathrm{mL}$ & $150 \times 10^{6} / \mathrm{mL}$ & $64.4 \times 10^{6} / \mathrm{mL}$ \\
\hline Cell viability at harvest & $98.0 \%$ & $98.9 \%$ & $97.8 \%$ & $97.2 \%$ & $98.9 \%$ \\
\hline Target VCC & $50 \times 10^{6} / \mathrm{mL}$ & $50 \times 10^{6} / \mathrm{mL}$ & $50 \times 10^{6} / \mathrm{mL}$ & $50 \times 10^{6} / \mathrm{mL}$ & $60 \times 10^{6} / \mathrm{mL}$ \\
\hline VCC when perfusion started & $6.9 \times 10^{6} / \mathrm{mL}$ & $2.6 \times 10^{6} / \mathrm{mL}$ & $2.8 \times 10^{6} / \mathrm{mL}$ & $3.11 \times 10^{6} / \mathrm{mL}$ & $2.3 \times 10^{6} / \mathrm{mL}$ \\
\hline $\begin{array}{l}\text { Cell viability when perfusion } \\
\text { started }\end{array}$ & $99.0 \%$ & $98.8 \%$ & $99.8 \%$ & $99.8 \%$ & $98.9 \%$ \\
\hline
\end{tabular}

TABLE 3. CHO-S cell culture feed tank and harvest tank volumes.

\begin{tabular}{|l|c|c|c|c|c|}
\hline \multicolumn{1}{|c|}{ Parameters } & Batch 1 & Batch 2 & Batch 3 & Batch 4 & Batch 5 \\
\hline Total volume of feed & $12.0 \mathrm{~L}$ & $22.0 \mathrm{~L}$ & $38.4 \mathrm{~L}$ & $50.0 \mathrm{~L}$ & $50.0 \mathrm{~L}$ \\
\hline Total volume of harvest & $4.0 \mathrm{~L}$ & $3.7 \mathrm{~L}$ & $3.64 \mathrm{~L}$ & $3.6 \mathrm{~L}$ & $3.6 \mathrm{~L}$ \\
\hline
\end{tabular}




\section{Results}

\section{DEVELOPMENT STUDIES}

\section{Performance of Batch 1}

During the initial 3 days of this culture run, the VCC and cell viability of the CHO-S cells decreased by 1 log (from $0.50-0.06 \times 10^{6} / \mathrm{mL}$ ) and the run was halted. The culture was removed, and the bag washed with sterile water. New media $(3.5 \mathrm{~L})$ was added $(\mathrm{pH} 7.05)$ and this run was restarted. It was hypothesized that poor culture performance was caused by the cell culture media being sensitive to $\mathrm{pH}(7.5-7.7)$, which led to precipitation and arrested cell growth. For the rest of this batch run, $\mathrm{pH}$ was maintained at 7.0 to determine if this would improve VCC and cell viability.

During the remaining part of this 6-day culture run, the VCC increased by $>1 \log$, from $0.6-14.5 \times 10^{6} / \mathrm{mL}$, and maintained $98 \%$ cell viability (Table 4 ), while glucose and lactate (measured from day 3 forward) were maintained between $2.0-2.5 \mathrm{~g} / \mathrm{L}$.

\section{Performance of Batch 2}

During the 10-day culture run of batch 2, the CHO-S
VCC increased by 2 logs, from $0.45-50.00 \times 10^{6} / \mathrm{mL}$, and cell viability was $98.9 \%$ at harvest (Table 5). Glucose (measured from day 3 forward) was maintained at $0.5-2.0 \mathrm{~g} / \mathrm{L}$, and lactate decreased from $1.3-0.4 \mathrm{~g} / \mathrm{L}$.

\section{Performance of Batch 3}

To determine reproducibility, cell culture batch 3 was run for 9 days using similar parameters to batch 2. Perfusion was not carried out on day 9 (the final day of the run), so no volume was exchanged. The VCC and CHO-S cell viability increased by 2 logs, from $0.45-50.00 \times 10^{6} / \mathrm{mL}$ (Table 6) with cells at $98.9 \%$ viability at harvest. Glucose (measured from day 3 ) was maintained at $0.50-2.77 \mathrm{~g} / \mathrm{L}$, and lactate decreased from $1.3-0.64 \mathrm{~g} / \mathrm{L}$. On day $7,500 \mathrm{~mL}$ of batch 3 (perfusion culture) was taken from the $5.25 \mathrm{~L}$ harvested volume to inoculate $38 \mathrm{~L}$ of proprietary media in a $50 \mathrm{~L}$ STR bioreactor. Production run 1 reached a peak VCC of $9.76 \times 10^{6} / \mathrm{mL}$ and $99.2 \%$ viability on day 11. The batch was harvested on day 16 with a VCC of $8.60 \times 10^{6} / \mathrm{mL}$ and $96.6 \%$ viability (Table 7 ).

\begin{tabular}{|c|c|c|c|c|c|c|c|c|}
\hline Day & $\begin{array}{c}\text { Initial } \\
\text { Media Volume }\end{array}$ & $\begin{array}{c}\text { Viable } \\
\text { Cell Count }\end{array}$ & $\begin{array}{c}\text { Cell } \\
\text { Viability }\end{array}$ & $\begin{array}{c}\text { Volume Taken/ } \\
\text { Harvested }\end{array}$ & $\begin{array}{l}\text { Volume } \\
\text { Added }\end{array}$ & $\begin{array}{c}\text { Perfusion } \\
\text { Rate* }\end{array}$ & $\begin{array}{l}\text { Rocker } \\
\text { Speed }\end{array}$ & $\begin{array}{c}\text { Rocker } \\
\text { Angle }\end{array}$ \\
\hline $\mathbf{0}$ & $4.00 \mathrm{~L}$ & $0.60 \times 10^{6} / \mathrm{mL}$ & $99.5 \%$ & $0 \mathrm{~L}$ & $0 \mathrm{~L}$ & 0 & 16 RPM & $6^{\circ}$ \\
\hline 1 & $3.98 \mathrm{~L}$ & $1.10 \times 10^{6} / \mathrm{mL}$ & $99.0 \%$ & $0 \mathrm{~L}$ & $0 \mathrm{~L}$ & 0 & 16 RPM & $6^{\circ}$ \\
\hline 2 & $3.97 \mathrm{~L}$ & $2.60 \times 10^{6} / \mathrm{mL}$ & $99.0 \%$ & $0 \mathrm{~L}$ & $0 \mathrm{~L}$ & 0 & 17 RPM & $6^{\circ}$ \\
\hline 3 & $3.96 \mathrm{~L}$ & $6.90 \times 10^{6} / \mathrm{mL}$ & $99.0 \%$ & $4 \mathrm{~L}$ & $4 \mathrm{~L}$ & 1 & 18 RPM & $7^{\circ}$ \\
\hline 4 & $4.00 \mathrm{~L}$ & $11.00 \times 10^{6} / \mathrm{mL}$ & $99.0 \%$ & $4 \mathrm{~L}$ & $4 \mathrm{~L}$ & 1 & 19 RPM & $7^{\circ}$ \\
\hline 5 & $4.00 \mathrm{~L}$ & $15.00 \times 10^{6} / \mathrm{mL}$ & $99.0 \%$ & $4 \mathrm{~L}$ & $4 \mathrm{~L}$ & 1 & $20 \mathrm{RPM}$ & $8^{\circ}$ \\
\hline 6 & $4.00 \mathrm{~L}$ & $14.50 \times 10^{6} / \mathrm{mL}$ & $98.0 \%$ & $0 \mathrm{~L}$ & $0 \mathrm{~L}$ & 0 & $21 \mathrm{RPM}$ & $10^{\circ}$ \\
\hline
\end{tabular}

\begin{tabular}{|c|c|c|c|c|c|c|c|c|}
\hline Day & $\begin{array}{c}\text { Initial } \\
\text { Media Volume }\end{array}$ & $\begin{array}{c}\text { Viable } \\
\text { Cell Count }\end{array}$ & $\begin{array}{c}\text { Cell } \\
\text { Viability }\end{array}$ & $\begin{array}{l}\text { Volume Taken/ } \\
\text { Harvested }\end{array}$ & $\begin{array}{l}\text { Volume } \\
\text { Added }\end{array}$ & $\begin{array}{c}\text { Perfusion } \\
\text { Rate* }\end{array}$ & $\begin{array}{l}\text { Rocker } \\
\text { Speed }\end{array}$ & $\begin{array}{c}\text { Rocker } \\
\text { Angle }\end{array}$ \\
\hline $\mathbf{0}$ & $4.00 \mathrm{~L}$ & $0.45 \times 10^{6} / \mathrm{mL}$ & $97.0 \%$ & $0 \mathrm{~L}$ & $0 \mathrm{~L}$ & 0.0 & 17 RPM & $6^{\circ}$ \\
\hline 1 & $3.98 \mathrm{~L}$ & $0.70 \times 10^{6} / \mathrm{mL}$ & $99.0 \%$ & $0 \mathrm{~L}$ & $0 \mathrm{~L}$ & 0.0 & 17 RPM & $6^{\circ}$ \\
\hline 2 & $3.97 \mathrm{~L}$ & $1.50 \times 10^{6} / \mathrm{mL}$ & $98.5 \%$ & $0 \mathrm{~L}$ & $0 \mathrm{~L}$ & 0.0 & $17 \mathrm{RPM}$ & $6^{\circ}$ \\
\hline 3 & $3.96 \mathrm{~L}$ & $3.20 \times 10^{6} / \mathrm{mL}$ & $98.8 \%$ & $2.00 \mathrm{~L}$ & $2.00 \mathrm{~L}$ & 0.5 & 18 RPM & $7^{\circ}$ \\
\hline 4 & $4.00 \mathrm{~L}$ & $6.00 \times 10^{6} / \mathrm{mL}$ & $99.1 \%$ & $4.00 \mathrm{~L}$ & $4.00 \mathrm{~L}$ & 1.0 & 19 RPM & $7^{\circ}$ \\
\hline 5 & $4.00 \mathrm{~L}$ & $9.91 \times 10^{6} / \mathrm{mL}$ & $98.8 \%$ & $4.00 \mathrm{~L}$ & $4.00 \mathrm{~L}$ & 1.0 & 20 RPM & $8^{\circ}$ \\
\hline 6 & $4.00 \mathrm{~L}$ & $17.10 \times 10^{6} / \mathrm{mL}$ & $99.3 \%$ & $6.00 \mathrm{~L}$ & $6.00 \mathrm{~L}$ & 1.5 & $21 \mathrm{RPM}$ & $8^{\circ}$ \\
\hline 7 & $4.00 \mathrm{~L}$ & $27.10 \times 10^{6} / \mathrm{mL}$ & $99.7 \%$ & $6.00 \mathrm{~L}$ & $6.00 \mathrm{~L}$ & 1.5 & 22 RPM & $9^{\circ}$ \\
\hline 8 & $3.50 \mathrm{~L}$ & $40.90 \times 10^{6} / \mathrm{mL}$ & $99.8 \%$ & $5.25 \mathrm{~L}$ & $5.25 \mathrm{~L}$ & 1.5 & $23 \mathrm{RPM}$ & $9^{\circ}$ \\
\hline 9 & $3.50 \mathrm{~L}$ & $45.00 \times 10^{6} / \mathrm{mL}$ & $99.2 \%$ & $7.00 \mathrm{~L}$ & $7.00 \mathrm{~L}$ & 2.0 & $23 \mathrm{RPM}$ & $9^{\circ}$ \\
\hline 10 & $3.50 \mathrm{~L}$ & $50.10 \times 10^{6} / \mathrm{mL}$ & $98.9 \%$ & $0 \mathrm{~L}$ & $0 \mathrm{~L}$ & 0.0 & $23 \mathrm{RPM}$ & $9^{\circ}$ \\
\hline \multicolumn{9}{|c|}{ *Bioreactor volumes per day } \\
\hline
\end{tabular}




\begin{tabular}{|c|c|c|c|c|c|c|c|c|}
\hline Day & $\begin{array}{c}\text { Initial } \\
\text { Media Volume }\end{array}$ & $\begin{array}{c}\text { Viable } \\
\text { Cell Count }\end{array}$ & $\begin{array}{c}\text { Cell } \\
\text { Viability }\end{array}$ & $\begin{array}{c}\text { Volume Taken/ } \\
\text { Harvested }\end{array}$ & $\begin{array}{l}\text { Volume } \\
\text { Added }\end{array}$ & $\begin{array}{l}\text { Perfusion } \\
\text { Rate* }\end{array}$ & $\begin{array}{l}\text { Rocker } \\
\text { Speed }\end{array}$ & $\begin{array}{c}\text { Rocker } \\
\text { Angle }\end{array}$ \\
\hline $\mathbf{0}$ & $3.90 \mathrm{~L}$ & $0.56 \times 10^{6} / \mathrm{mL}$ & $98.7 \%$ & $0.00 \mathrm{~L}$ & $0.00 \mathrm{~L}$ & 0.0 & 16 RPM & $6^{\circ}$ \\
\hline 1 & $3.88 \mathrm{~L}$ & ND & ND & $0.00 \mathrm{~L}$ & $0.00 \mathrm{~L}$ & 0.0 & 16 RPM & $6^{\circ}$ \\
\hline 2 & $3.86 \mathrm{~L}$ & $2.32 \times 10^{6} / \mathrm{mL}$ & $99.7 \%$ & $0.00 \mathrm{~L}$ & $0.00 \mathrm{~L}$ & 0.0 & 16 RPM & $6^{\circ}$ \\
\hline 3 & $3.84 \mathrm{~L}$ & $4.28 \times 10^{6} / \mathrm{mL}$ & $99.8 \%$ & $2.20 \mathrm{~L}$ & $2.20 \mathrm{~L}$ & 0.5 & 18 RPM & $6^{\circ}$ \\
\hline 4 & $3.82 \mathrm{~L}$ & $6.42 \times 10^{6} / \mathrm{mL}$ & $99.5 \%$ & $3.80 \mathrm{~L}$ & $3.80 \mathrm{~L}$ & 1.0 & 19 RPM & $7^{\circ}$ \\
\hline 5 & $3.80 \mathrm{~L}$ & $12.50 \times 10^{6} / \mathrm{mL}$ & $99.2 \%$ & $3.80 \mathrm{~L}$ & $3.80 \mathrm{~L}$ & 1.0 & 19 RPM & $7^{\circ}$ \\
\hline 6 & $3.78 \mathrm{~L}$ & $25.30 \times 10^{6} / \mathrm{mL}$ & $99.6 \%$ & $5.67 \mathrm{~L}$ & $5.67 \mathrm{~L}$ & 1.5 & 20 RPM & $8^{\circ}$ \\
\hline 7 & $3.76 \mathrm{~L}$ & $41.80 \times 10^{6} / \mathrm{mL}$ & $99.7 \%$ & $7.50 \mathrm{~L}$ & $7.50 \mathrm{~L}$ & 2.0 & $21 \mathrm{RPM}$ & $8^{\circ}$ \\
\hline 8 & $3.16 \mathrm{~L}$ & $67.50 \times 10^{6} / \mathrm{mL}$ & $98.7 \%$ & $7.00 \mathrm{~L}$ & $7.00 \mathrm{~L}$ & 2.0 & 23 RPM & $9^{\circ}$ \\
\hline 9 & $3.14 \mathrm{~L}$ & $53.50 \times 10^{6} / \mathrm{mL}$ & $92.2 \%$ & $0.00 \mathrm{~L}$ & $0.00 \mathrm{~L}$ & 0.0 & $23 \mathrm{RPM}$ & $9^{\circ}$ \\
\hline \multicolumn{9}{|c|}{ NOTE: No data (ND) *Bioreactor volumes per day } \\
\hline
\end{tabular}

TABLE 7. 16-day production run 1 data: CHO-S cells cultured in the STR $50 \mathrm{~L}$ bioreactor seeded with batch 3 intensified (50 L perfusion) material.

\begin{tabular}{|c|c|c|c|c|c|c|}
\hline Day & Viable Cell Count & Cell Viability & Lactate & Residual Glucose & $\mathrm{pCO}_{2}$ & mAb Titer Achieved \\
\hline $\mathbf{0}$ & $0.36 \times 10^{6} / \mathrm{mL}$ & $99.4 \%$ & $0.00 \mathrm{~g} / \mathrm{L}$ & $5.30 \mathrm{~g} / \mathrm{L}$ & ND & \\
\hline 1 & $0.64 \times 10^{6} / \mathrm{mL}$ & $99.5 \%$ & $0.25 \mathrm{~g} / \mathrm{L}$ & $5.10 \mathrm{~g} / \mathrm{L}$ & $18.7 \mathrm{mmHg}$ & \\
\hline 2 & $0.98 \times 10^{6} / \mathrm{mL}$ & $94.4 \%$ & $0.45 \mathrm{~g} / \mathrm{L}$ & $4.87 \mathrm{~g} / \mathrm{L}$ & $24.5 \mathrm{mmHg}$ & \\
\hline 3 & $2.08 \times 10^{6} / \mathrm{mL}$ & $96.3 \%$ & $0.77 \mathrm{~g} / \mathrm{L}$ & $4.34 \mathrm{~g} / \mathrm{L}$ & $33.3 \mathrm{mmHg}$ & \\
\hline 4 & $3.60 \times 10^{6} / \mathrm{mL}$ & $98.8 \%$ & $1.27 \mathrm{~g} / \mathrm{L}$ & $3.70 \mathrm{~g} / \mathrm{L}$ & $32.9 \mathrm{mmHg}$ & \\
\hline 5 & $4.85 \times 10^{6} / \mathrm{mL}$ & $99.8 \%$ & $1.05 \mathrm{~g} / \mathrm{L}$ & $2.81 \mathrm{~g} / \mathrm{L}$ & $57.2 \mathrm{mmHg}$ & \\
\hline 6 & $6.20 \times 10^{6} / \mathrm{mL}$ & $99.7 \%$ & $1.12 \mathrm{~g} / \mathrm{L}$ & $2.14 \mathrm{~g} / \mathrm{L}$ & $31.6 \mathrm{mmHg}$ & \\
\hline 7 & $7.48 \times 10^{6} / \mathrm{mL}$ & $99.7 \%$ & $1.02 \mathrm{~g} / \mathrm{L}$ & $1.54 \mathrm{~g} / \mathrm{L}$ & $37.4 \mathrm{mmHg}$ & \\
\hline 8 & $8.59 \times 10^{6} / \mathrm{mL}$ & $99.5 \%$ & $0.75 \mathrm{~g} / \mathrm{L}$ & $1.26 \mathrm{~g} / \mathrm{L}$ & $43.2 \mathrm{mmHg}$ & \\
\hline 9 & $9.32 \times 10^{6} / \mathrm{mL}$ & $99.6 \%$ & $0.56 \mathrm{~g} / \mathrm{L}$ & $1.19 \mathrm{~g} / \mathrm{L}$ & $47.9 \mathrm{mmHg}$ & \\
\hline 10 & $9.30 \times 10^{6} / \mathrm{mL}$ & $99.2 \%$ & $0.45 \mathrm{~g} / \mathrm{L}$ & $1.02 \mathrm{~g} / \mathrm{L}$ & $44.2 \mathrm{mmHg}$ & \\
\hline 11 & $9.76 \times 10^{6} / \mathrm{mL}$ & $99.2 \%$ & $0.23 \mathrm{~g} / \mathrm{L}$ & $1.10 \mathrm{~g} / \mathrm{L}$ & $48.2 \mathrm{mmHg}$ & \\
\hline 12 & $9.22 \times 10^{6} / \mathrm{mL}$ & $99.1 \%$ & $0.22 \mathrm{~g} / \mathrm{L}$ & $1.02 \mathrm{~g} / \mathrm{L}$ & $51.2 \mathrm{mmHg}$ & \\
\hline 13 & $9.10 \times 10^{6} / \mathrm{mL}$ & $98.8 \%$ & $0.25 \mathrm{~g} / \mathrm{L}$ & $1.08 \mathrm{~g} / \mathrm{L}$ & $45.4 \mathrm{mmHg}$ & \\
\hline 14 & $8.80 \times 10^{6} / \mathrm{mL}$ & $98.8 \%$ & $0.34 \mathrm{~g} / \mathrm{L}$ & $1.01 \mathrm{~g} / \mathrm{L}$ & $39.7 \mathrm{mmHg}$ & \\
\hline 15 & $8.90 \times 10^{6} / \mathrm{mL}$ & $98.8 \%$ & $0.41 \mathrm{~g} / \mathrm{L}$ & $1.18 \mathrm{~g} / \mathrm{L}$ & $38.4 \mathrm{mmHg}$ & \\
\hline 16 & $8.60 \times 10^{6} / \mathrm{mL}$ & $96.6 \%$ & $0.56 \mathrm{~g} / \mathrm{L}$ & $1.16 \mathrm{~g} / \mathrm{L}$ & $37.4 \mathrm{mmHg}$ & $1.18 \mathrm{~g} / \mathrm{L}$ \\
\hline
\end{tabular}

\section{Performance of Batch 4}

CHO-S cell culture batch 4 was run for a total of 8 days. All conditions were similar to batches 2 and 3, with the exception of the perfusion rates, which were increased from 2-3 bioreactor volumes per day. The cells maintained good viability at $99.2-99.8 \%$ and VCC increased by $3 \operatorname{logs}$, from $0.49-150 \times 10^{6} / \mathrm{mL}$ (Table 8), which was more than double that of batches 2 and 3 at harvest. On day 7, $500 \mathrm{~mL}$ of batch 4 material was taken from the $7 \mathrm{~L}$ harvested volume to inoculate $38 \mathrm{~L}$ of proprietary media in a $50 \mathrm{~L}$ STR bioreactor. Production run 2 VCC reached a peak of $7.70 \times 10^{6} / \mathrm{mL}$ with $99.20 \%$ viability on day 9 . The batch was harvested on day 16 with a VCC of $6.29 \times 10^{6} / \mathrm{mL}$ and $91.40 \%$ viability (Table 9).

\section{Development Study Summary}

Results from development batches 1-4 showed that the optimum intensified conditions for culturing CHO-S cells expressing a mAb biosimilar were: (1) 1-3 volumes per day of proprietary media in a culture run of 6-7 days; (2) a rocker speed increase from 16-23 RPM; (3) a rocker angle of $6-10^{\circ}$; and (4) a pH of 6.9 to prevent loss of cell viability. These optimized strategies were used for batches 2 and 3, achieving a VCC of $50-67 \times 10^{6} / \mathrm{mL}$ with $98 \%$ viability. Batch 4 , where the perfusion rate was increased to 3 bioreactor volumes on day 6 , achieved the best results, with a VCC of $150 \times 10^{6} / \mathrm{mL}$ and viability of 99.3\% (Figure 2). 


\begin{tabular}{|c|c|c|c|c|c|c|c|c|}
\hline \multicolumn{7}{|c|}{ TABLE 8. CHO-S cell perfusion batch 4: VCC and cell viability data from an 8-day run. } \\
\hline Day & $\begin{array}{c}\text { Initial } \\
\text { Media Volume }\end{array}$ & $\begin{array}{c}\text { Viable } \\
\text { Cell Count }\end{array}$ & $\begin{array}{c}\text { Cell } \\
\text { Viability }\end{array}$ & $\begin{array}{c}\text { Volume Taken/ } \\
\text { Harvested }\end{array}$ & $\begin{array}{c}\text { Volume } \\
\text { Added }\end{array}$ & $\begin{array}{c}\text { Perfusion } \\
\text { Rate** }\end{array}$ & $\begin{array}{c}\text { Rocker } \\
\text { Speed }\end{array}$ & $\begin{array}{c}\text { Rocker } \\
\text { Angle }\end{array}$ \\
\hline $\mathbf{0}$ & $4.00 \mathrm{~L}$ & $0.49 \times 10^{6} / \mathrm{mL}$ & $99.5 \%$ & $0.0 \mathrm{~L}$ & $0.0 \mathrm{~L}$ & ND & $16 \mathrm{RPM}$ & $6^{\circ}$ \\
\hline $\mathbf{1}$ & $3.98 \mathrm{~L}$ & $0.71 \times 10^{6} / \mathrm{mL}$ & $99.2 \%$ & $0.0 \mathrm{~L}$ & $0.0 \mathrm{~L}$ & $\mathrm{ND}$ & $16 \mathrm{RPM}$ & $6^{\circ}$ \\
\hline $\mathbf{2}$ & $3.97 \mathrm{~L}$ & $1.55 \times 10^{6} / \mathrm{mL}$ & $99.3 \%$ & $4.0 \mathrm{~L}$ & $4.0 \mathrm{~L}$ & 1.0 & $16 \mathrm{RPM}$ & $6^{\circ}$ \\
\hline $\mathbf{3}$ & $3.96 \mathrm{~L}$ & $3.11 \times 10^{6} / \mathrm{mL}$ & $99.8 \%$ & $6.0 \mathrm{~L}$ & $6.0 \mathrm{~L}$ & 1.5 & $16 \mathrm{RPM}$ & $6^{\circ}$ \\
\hline $\mathbf{4}$ & $4.00 \mathrm{~L}$ & $6.32 \times 10^{6} / \mathrm{mL}$ & $99.5 \%$ & $8.0 \mathrm{~L}$ & $8.0 \mathrm{~L}$ & 2.0 & $19 \mathrm{RPM}$ & $8^{\circ}$ \\
\hline $\mathbf{5}$ & $4.00 \mathrm{~L}$ & $13.50 \times 10^{6} / \mathrm{mL}$ & $99.4 \%$ & $10.0 \mathrm{~L}$ & $10.0 \mathrm{~L}$ & 2.5 & $20 \mathrm{RPM}$ & $9^{\circ}$ \\
\hline $\mathbf{6}$ & $4.00 \mathrm{~L}$ & $30.67 \times 10^{6} / \mathrm{mL}$ & $99.5 \%$ & $12.0 \mathrm{~L}$ & $12.0 \mathrm{~L}$ & 3.0 & $21 \mathrm{RPM}$ & $10^{\circ}$ \\
\hline $\mathbf{7}$ & $4.00 \mathrm{~L}$ & $68.25 \times 10^{6} / \mathrm{mL}$ & $99.5 \%$ & $12.0 \mathrm{~L}$ & $12.0 \mathrm{~L}$ & 3.0 & $22 \mathrm{RPM}$ & $10^{\circ}$ \\
\hline $\mathbf{8}$ & $3.50 \mathrm{~L}$ & $150.00 \times 10^{6} / \mathrm{mL}$ & $99.3 \%$ & $11.5 \mathrm{~L}$ & $11.5 \mathrm{~L}$ & 3.0 & $23 \mathrm{RPM}$ & $10^{\circ}$ \\
\hline
\end{tabular}

\section{TABLE 9. 16-day production run 2 data: CHO-S cells cultured in STR $50 \mathrm{~L}$ bioreactor seeded with batch 4 intensified material.}

\begin{tabular}{|c|c|c|c|c|c|c|}
\hline Day & Viable Cell Count & Cell Viability & Lactate & Residual Glucose & $\mathrm{pCO}_{2}$ & mAb Titer Achieved \\
\hline $\mathbf{0}$ & $0.52 \times 10^{6} / \mathrm{mL}$ & $98.1 \%$ & $0.05 \mathrm{~g} / \mathrm{L}$ & $5.36 \mathrm{~g} / \mathrm{L}$ & $19.6 \mathrm{mmHg}$ & \\
\hline 1 & $0.72 \times 10^{6} / \mathrm{mL}$ & $99.1 \%$ & $0.19 \mathrm{~g} / \mathrm{L}$ & $5.31 \mathrm{~g} / \mathrm{L}$ & $42.2 \mathrm{mmHg}$ & \\
\hline 2 & $0.91 \times 10^{6} / \mathrm{mL}$ & $98.9 \%$ & $0.50 \mathrm{~g} / \mathrm{L}$ & $4.55 \mathrm{~g} / \mathrm{L}$ & ND & \\
\hline 3 & $2.17 \times 10^{6} / \mathrm{mL}$ & $98.2 \%$ & $1.10 \mathrm{~g} / \mathrm{L}$ & $3.36 \mathrm{~g} / \mathrm{L}$ & $31.0 \mathrm{mmHg}$ & \\
\hline 4 & $4.20 \times 10^{6} / \mathrm{mL}$ & $99.8 \%$ & $1.47 \mathrm{~g} / \mathrm{L}$ & $2.65 \mathrm{~g} / \mathrm{L}$ & $22.2 \mathrm{mmHg}$ & \\
\hline 5 & $5.33 \times 10^{6} / \mathrm{mL}$ & $98.9 \%$ & $1.29 \mathrm{~g} / \mathrm{L}$ & $2.05 \mathrm{~g} / \mathrm{L}$ & $34.8 \mathrm{mmHg}$ & \\
\hline 6 & $6.75 \times 10^{6} / \mathrm{mL}$ & $99.1 \%$ & $1.10 \mathrm{~g} / \mathrm{L}$ & $1.39 \mathrm{~g} / \mathrm{L}$ & $22.1 \mathrm{mmHg}$ & \\
\hline 7 & $7.55 \times 10^{6} / \mathrm{mL}$ & $98.7 \%$ & $0.72 \mathrm{~g} / \mathrm{L}$ & $1.15 \mathrm{~g} / \mathrm{L}$ & $42.5 \mathrm{mmHg}$ & \\
\hline 8 & $7.12 \times 10^{6} / \mathrm{mL}$ & $98.8 \%$ & $0.50 \mathrm{~g} / \mathrm{L}$ & $1.03 \mathrm{~g} / \mathrm{L}$ & $37.8 \mathrm{mmHg}$ & \\
\hline 9 & $7.70 \times 10^{6} / \mathrm{mL}$ & $98.5 \%$ & $0.34 \mathrm{~g} / \mathrm{L}$ & $1.01 \mathrm{~g} / \mathrm{L}$ & $51.9 \mathrm{mmHg}$ & \\
\hline 10 & $7.35 \times 10^{6} / \mathrm{mL}$ & $98.0 \%$ & $0.21 \mathrm{~g} / \mathrm{L}$ & $0.88 \mathrm{~g} / \mathrm{L}$ & $39.5 \mathrm{mmHg}$ & \\
\hline 11 & $7.21 \times 10^{6} / \mathrm{mL}$ & $99.2 \%$ & $0.23 \mathrm{~g} / \mathrm{L}$ & $1.10 \mathrm{~g} / \mathrm{L}$ & $48.2 \mathrm{mmHg}$ & \\
\hline 12 & $7.20 \times 10^{6} / \mathrm{mL}$ & $97.0 \%$ & $0.20 \mathrm{~g} / \mathrm{L}$ & $0.95 \mathrm{~g} / \mathrm{L}$ & $62.7 \mathrm{mmHg}$ & \\
\hline 13 & $7.02 \times 10^{6} / \mathrm{mL}$ & $97.0 \%$ & $0.08 \mathrm{~g} / \mathrm{L}$ & $0.94 \mathrm{~g} / \mathrm{L}$ & $67.3 \mathrm{mmHg}$ & \\
\hline 14 & $6.85 \times 10^{6} / \mathrm{mL}$ & $94.9 \%$ & $0.12 \mathrm{~g} / \mathrm{L}$ & $0.88 \mathrm{~g} / \mathrm{L}$ & $29.8 \mathrm{mmHg}$ & \\
\hline 15 & $6.54 \times 10^{6} / \mathrm{mL}$ & $93.6 \%$ & $0.34 \mathrm{~g} / \mathrm{L}$ & $1.29 \mathrm{~g} / \mathrm{L}$ & $31.3 \mathrm{mmHg}$ & \\
\hline 16 & $6.29 \times 10^{6} / \mathrm{mL}$ & $91.4 \%$ & ND & ND & ND & $1.20 \mathrm{~g} / \mathrm{L}$ \\
\hline
\end{tabular}

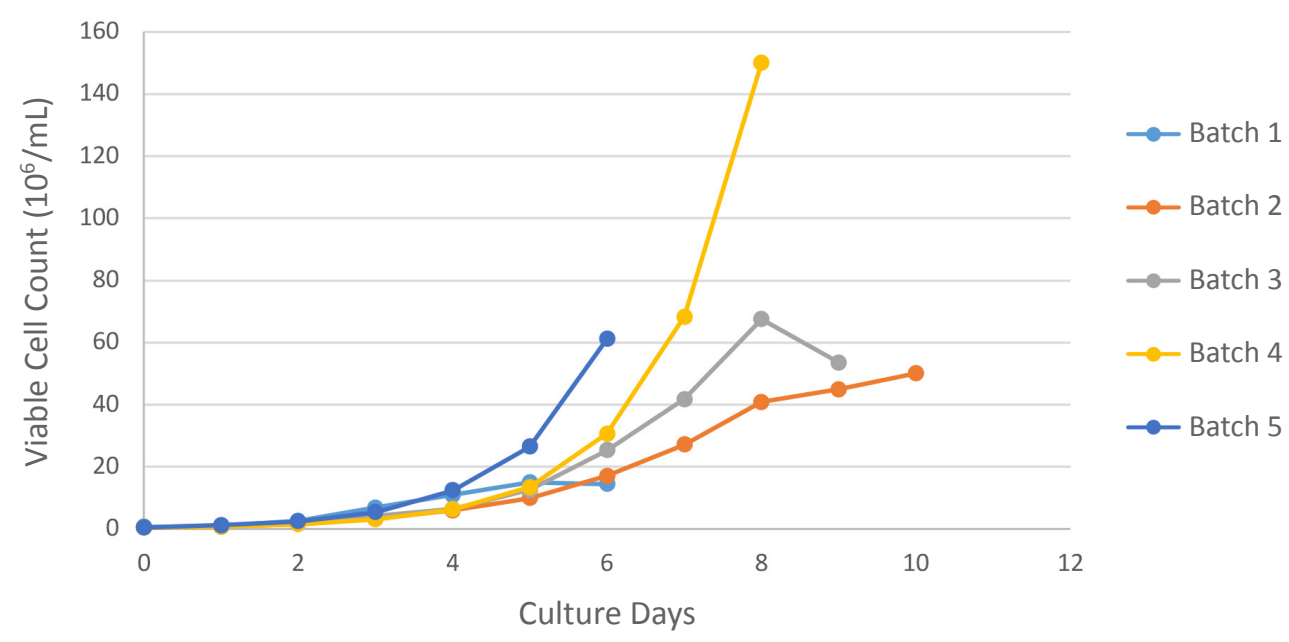

FIGURE 2. VCC of CHO-S cells in five perfusion culture development batch runs. 


\section{CONFIRMATION STUDY}

\section{Performance of Batch 5}

Perfusion CHO-S cell culture batch 5 was run for 6 days with conditions similar to batch 4 , which achieved the highest VCC, as compared to the previous four batches. The VCC for batch 5 reached $61.2 \times 10^{6} / \mathrm{mL}$ while maintaining good viability, which was $99.3 \%$ on the final day 6 (Table 10). At that point, $500 \mathrm{~mL}$ of batch 5 was taken from the $9.5 \mathrm{~L}$ harvested volume to inoculate $38 \mathrm{~L}$ of proprietary media in a 50 L STR bioreactor. Production run 3 achieved a peak VCC of $9.30 \times 10^{6} / \mathrm{mL}$ with a viability of $95.70 \%$ on day 13 . The batch was harvested on day 16 with a VCC of $7.85 \times 10^{6} / \mathrm{mL}$ and $97.20 \%$ viability (Table 11 and Figures $3 A$ and $3 \mathbf{B}$ ). These $\mathrm{CHO}-\mathrm{S}$ cell culture results are comparable in performance (VCC, viability, glucose, and lactate) to batches produced by Intas following inoculation with the control cells expanded via fed-batch (Table 11 and Figures 4A and 4B). A sparge ventilation was used to remove headspace $\mathrm{CO}_{2}$ in both runs, but $\mathrm{pCO}_{2}$ levels in the control run oscillated more than the intensified run (Figure 5), as different proprietary flow rates were used to remove $\mathrm{CO}_{2}$ in each run. Overall titers (Figure 6) and CQAs (data not shown) of the $\mathrm{mAb}$ product were also similar, with total galactosylation of $57 \%$ in the $\mathrm{mAb}$ derived from the control culture, compared to $54.5 \%$ from the intensified seed train culture.

\section{Confirmation Study Summary}

CHO-S cells cultured in the SU 50 L STR bioreactor performed well, following inoculation with the intensified (perfusion) seed train product, indicating that this approach can be used for a hybrid perfusion/fed-batch process scale-up.

\begin{tabular}{|c|c|c|c|c|c|c|c|c|}
\hline Day & $\begin{array}{c}\text { Initial } \\
\text { Media Volume }\end{array}$ & $\begin{array}{c}\text { Viable } \\
\text { Cell Count }\end{array}$ & $\begin{array}{c}\text { Cell } \\
\text { Viability }\end{array}$ & $\begin{array}{c}\text { Volume Taken/ } \\
\text { Harvested }\end{array}$ & $\begin{array}{l}\text { Volume } \\
\text { Added }\end{array}$ & $\begin{array}{l}\text { Perfusion } \\
\text { Rate* }\end{array}$ & $\begin{array}{l}\text { Rocker } \\
\text { Speed }\end{array}$ & $\begin{array}{c}\text { Rocker } \\
\text { Angle }\end{array}$ \\
\hline $\mathbf{0}$ & $4 \mathrm{~L}$ & $0.48 \times 10^{6} / \mathrm{mL}$ & $99.0 \%$ & $0.0 \mathrm{~L}$ & $0.0 \mathrm{~L}$ & ND & 16 RPM & $6^{\circ}$ \\
\hline 1 & $4 \mathrm{~L}$ & $1.15 \times 10^{6} / \mathrm{mL}$ & $98.5 \%$ & $0.0 \mathrm{~L}$ & $0.0 \mathrm{~L}$ & ND & $16 \mathrm{RPM}$ & $6^{\circ}$ \\
\hline 2 & $4 \mathrm{~L}$ & $2.30 \times 10^{6} / \mathrm{mL}$ & $98.8 \%$ & $0.0 \mathrm{~L}$ & $0.0 \mathrm{~L}$ & 1.0 & 17 RPM & $7^{\circ}$ \\
\hline 3 & $4 \mathrm{~L}$ & $5.35 \times 10^{6} / \mathrm{mL}$ & $99.4 \%$ & $3.9 \mathrm{~L}$ & $3.9 \mathrm{~L}$ & 1.5 & 18 RPM & $8^{\circ}$ \\
\hline 4 & $4 \mathrm{~L}$ & $12.40 \times 10^{6} / \mathrm{mL}$ & $99.3 \%$ & $5.9 \mathrm{~L}$ & $5.9 \mathrm{~L}$ & 2.0 & 19 RPM & $9^{\circ}$ \\
\hline 5 & $4 \mathrm{~L}$ & $26.50 \times 10^{6} / \mathrm{mL}$ & $99.4 \%$ & $7.6 \mathrm{~L}$ & $7.6 \mathrm{~L}$ & 2.5 & 20 RPM & $10^{\circ}$ \\
\hline 6 & $4 \mathrm{~L}$ & $61.20 \times 10^{6} / \mathrm{mL}$ & $99.3 \%$ & $9.5 \mathrm{~L}$ & $9.5 \mathrm{~L}$ & ND & 20 RPM & $10^{\circ}$ \\
\hline \multicolumn{9}{|c|}{ *Bioreactor volumes per day } \\
\hline
\end{tabular}

TABLE 11. 16-day production run 3 data: A comparison of CHO-S cell culture performance using STR 50 L bioreactors seeded separately with the control (used as seed to inoculate the $4000 \mathrm{~L}$ fed-batch process) and intensified ( $50 \mathrm{~L}$ perfusion) materials.

\begin{tabular}{|c|c|c|c|c|c|c|c|c|c|c|c|c|}
\hline \multirow{2}{*}{ Day } & \multicolumn{2}{|c|}{$\begin{array}{c}\text { VCC } \\
\left(\times 10^{6} / \mathrm{mL}\right)\end{array}$} & \multicolumn{2}{|c|}{$\begin{array}{c}\text { Cell Viability } \\
(\%)\end{array}$} & \multicolumn{2}{|c|}{$\begin{array}{l}\text { Accumulated } \\
\text { Lactate }(g / L)\end{array}$} & \multicolumn{2}{|c|}{$\begin{array}{c}\text { Residual } \\
\text { Glucose }(\mathrm{g} / \mathrm{L})\end{array}$} & \multicolumn{2}{|c|}{$\begin{array}{c}\mathrm{pCO}_{2} \\
(\mathrm{mmHg})\end{array}$} & \multicolumn{2}{|c|}{$\begin{array}{c}\text { mAb Titer } \\
\text { Achieved }(\mathrm{g} / \mathrm{L})\end{array}$} \\
\hline & Control & $50 \mathrm{~L}$ & Control & $50 \mathrm{~L}$ & Control & $50 \mathrm{~L}$ & Control & $50 \mathrm{~L}$ & Control & $50 \mathrm{~L}$ & Control & $50 \mathrm{~L}$ \\
\hline $\mathbf{0}$ & 0.52 & 0.60 & 98.11 & 99.90 & 0.05 & 0.04 & 5.36 & 5.29 & 19.60 & 45.70 & & \\
\hline 1 & 0.72 & 1.20 & 99.10 & 99.40 & 0.19 & 0.19 & 5.31 & 5.25 & 42.20 & 87.10 & & \\
\hline 2 & 0.91 & 2.81 & 98.91 & 99.60 & 0.50 & 0.77 & 4.55 & 4.07 & ND & 34.40 & & \\
\hline 3 & 2.17 & 5.45 & 98.19 & 99.20 & 1.10 & 1.15 & 3.36 & 3.02 & 31.00 & 25.70 & & \\
\hline 4 & 4.20 & 6.88 & 99.76 & 99.80 & 1.47 & 1.17 & 2.65 & 2.97 & 22.20 & 32.40 & & \\
\hline 5 & 5.33 & 7.52 & 98.89 & 99.70 & 1.29 & 0.96 & 2.05 & 2.50 & 34.80 & 38.50 & & \\
\hline 6 & 6.75 & 7.55 & 99.12 & 99.60 & 1.10 & 0.74 & 1.39 & 2.43 & 22.10 & 52.90 & & \\
\hline 7 & 7.55 & 8.02 & 98.69 & 99.60 & 0.72 & 0.50 & 1.15 & 1.95 & 42.50 & 45.80 & & \\
\hline 8 & 7.12 & 9.12 & 98.80 & 99.20 & 0.50 & 0.32 & 1.03 & 1.66 & 37.80 & 52.70 & & \\
\hline 9 & 7.70 & 9.06 & 98.50 & 99.60 & 0.34 & 0.21 & 1.01 & 1.30 & 51.90 & 49.80 & & \\
\hline 10 & 7.35 & 8.72 & 98.00 & 99.60 & 0.21 & 0.10 & 0.88 & 1.37 & 39.50 & 54.20 & & \\
\hline 11 & 7.21 & 9.12 & 97.00 & 99.20 & 0.20 & 0.07 & 0.95 & 1.01 & 62.70 & 55.50 & & \\
\hline 12 & 7.20 & 8.51 & 97.00 & 99.20 & 0.08 & 0.07 & 0.94 & 1.27 & 67.30 & 52.10 & & \\
\hline 13 & 7.02 & 9.30 & 95.70 & 99.10 & 0.09 & 0.08 & 0.99 & 1.10 & 52.90 & 49.80 & & \\
\hline 14 & 6.85 & 8.19 & 94.90 & 99.00 & 0.12 & 0.09 & 0.88 & 1.20 & 29.80 & 51.20 & & \\
\hline 15 & 6.54 & 7.91 & 93.60 & 98.90 & 0.34 & 0.10 & 1.29 & 1.22 & 31.30 & 53.20 & & \\
\hline 16 & 6.29 & 7.85 & 91.40 & 97.20 & ND & 0.12 & ND & 1.20 & ND & 50.80 & 1.34 & 1.42 \\
\hline
\end{tabular}



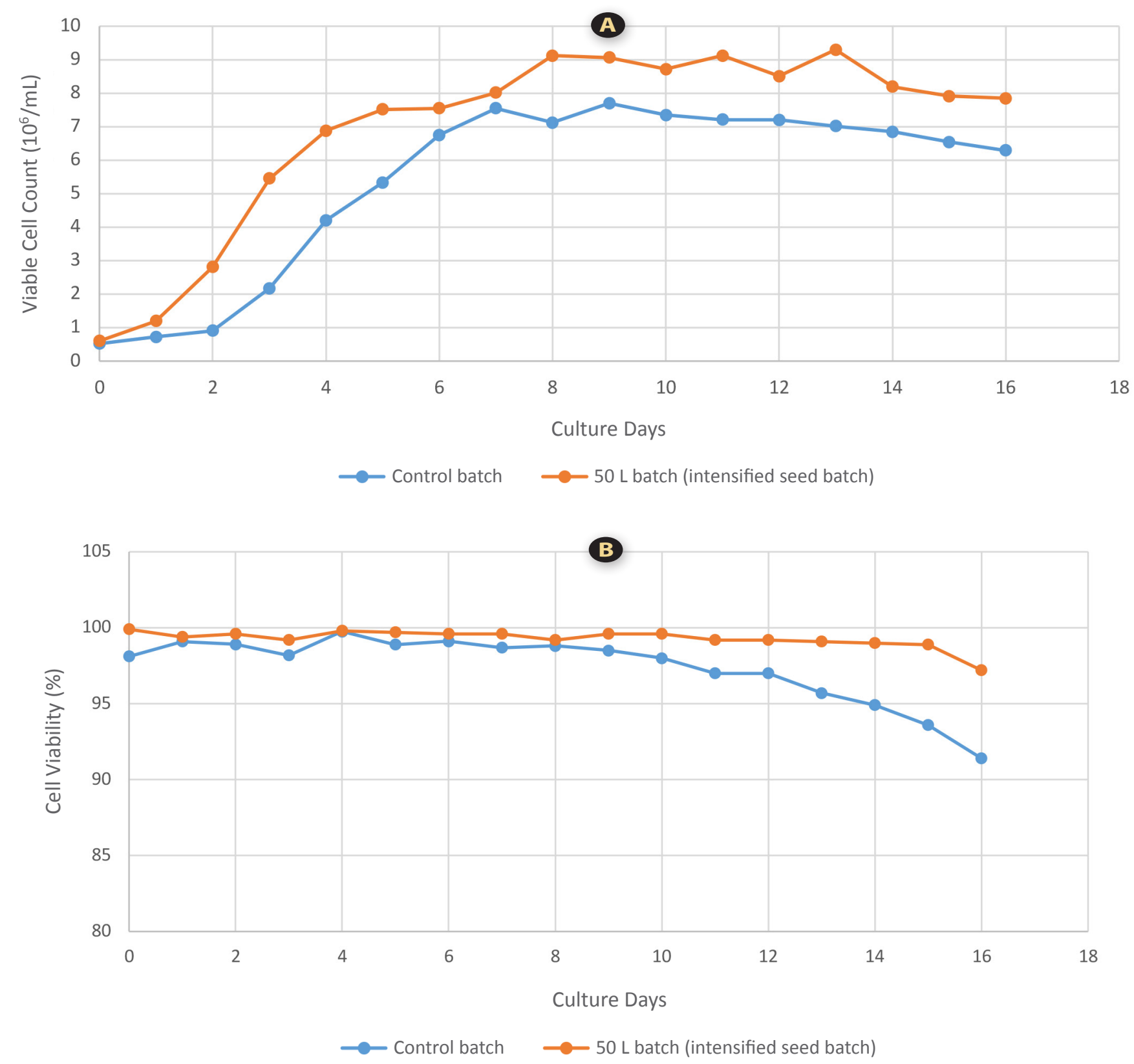

FIGURE 3. 16-day production run 3 data comparing: (A) VCC; and (B) cell viability in CHO-S cells cultured using STR $50 \mathrm{~L}$ bioreactors seeded separately with the control and intensified materials. 

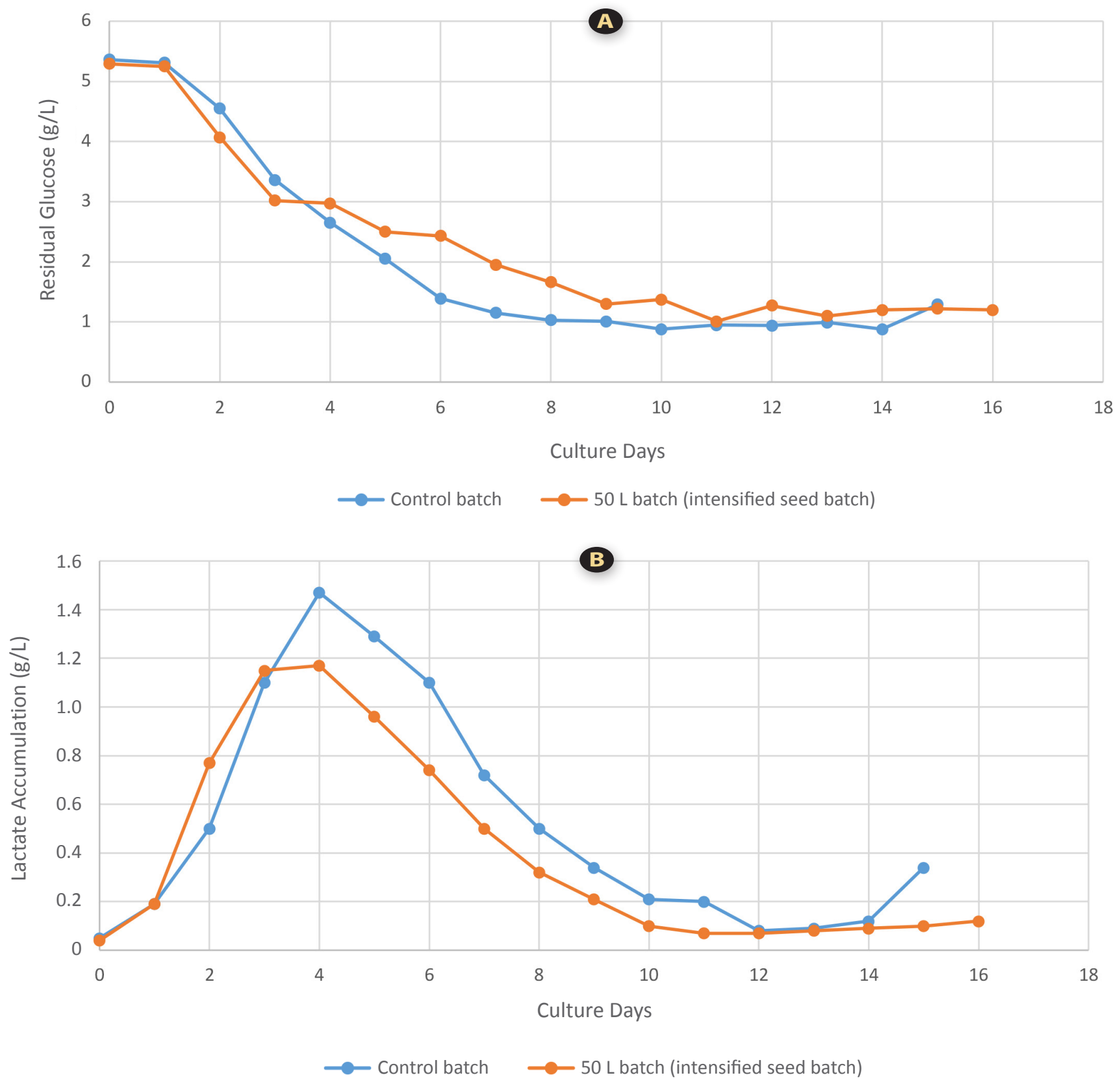

FIGURE 4. 16-day production run 3 data comparing: (A) residual glucose; and (B) lactate accumulation in CHO-S cells cultured using STR $50 \mathrm{~L}$ bioreactors seeded separately with the control and intensified materials. 


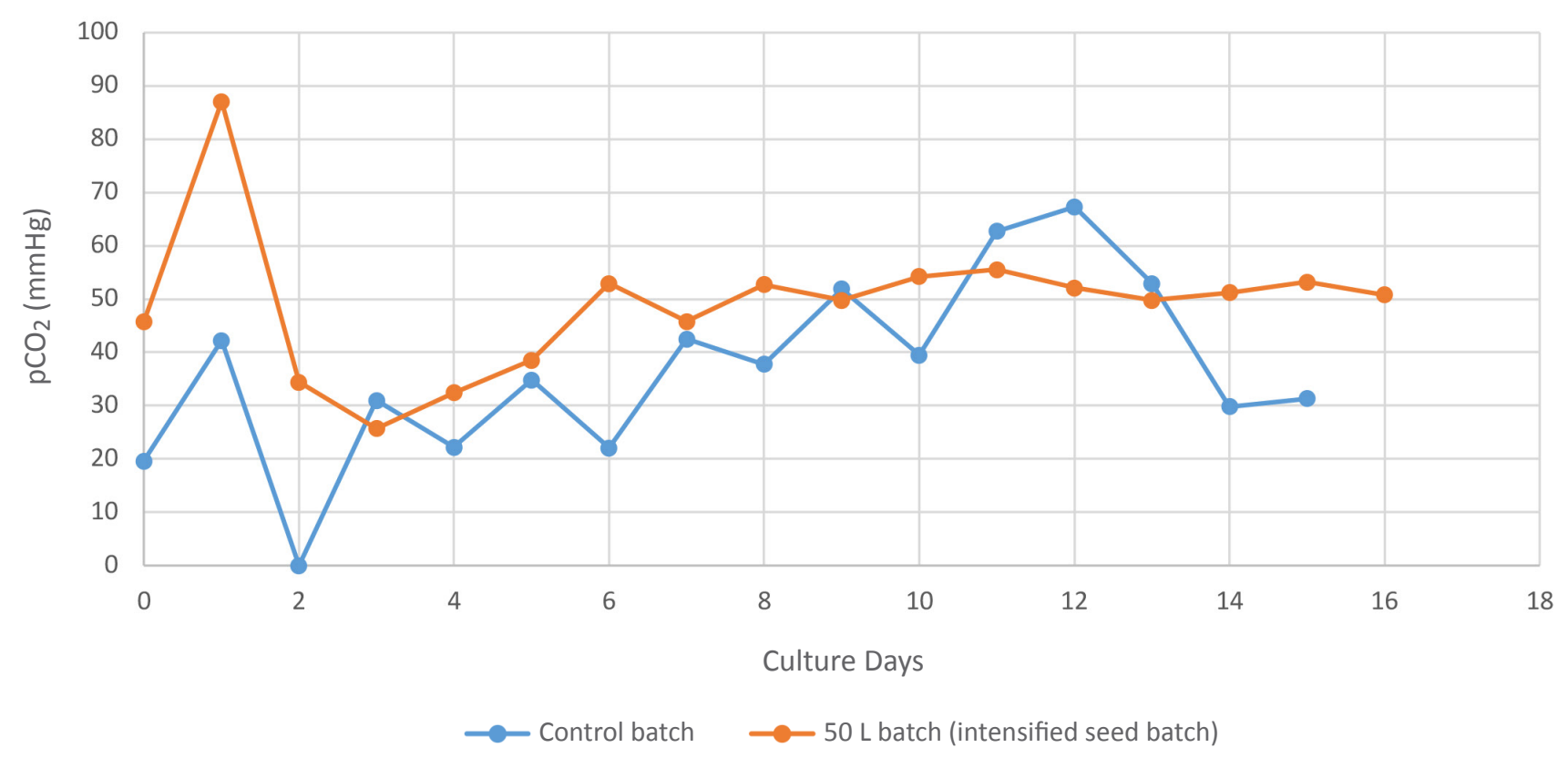

FIGURE 5. 16-day production run 3 data comparing $\mathrm{pCO}_{2}$ in $\mathrm{CHO}-\mathrm{S}$ cells cultured using STR $50 \mathrm{~L}$ bioreactors seeded separately with the control and intensified materials.

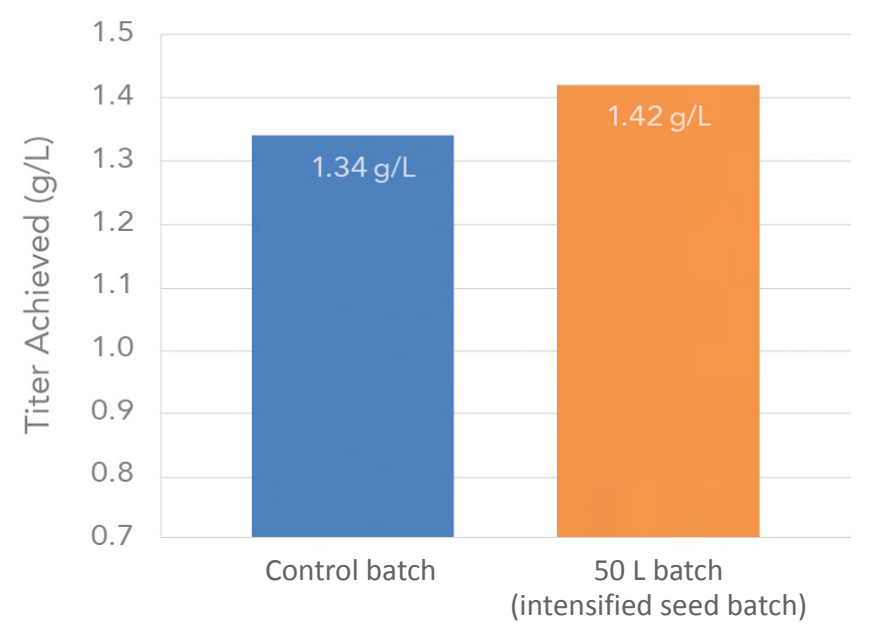

FIGURE 6. 16-day production run 3 data comparing CHO-S cell mAb titers using STR 50 L bioreactors seeded separately with the control and intensified materials. 


\section{Discussion}

At Intas, when using a standard fed-batch seed train production protocol, the VCC typically reaches $7-8 \times 10^{6} / \mathrm{mL}$ after 14-16 days of fed-batch culture with the CHO-S clone and media used as a control in this study. By intensifying the seed train cell expansion via perfusion technology, it is possible to achieve a ten-fold increase in VCC at N-1 seed stage compared to the control batch just described, in only 6-8 days. This is consistent with other studies where very high cell densities $\left(\geq 40-100 \times 10^{6} / \mathrm{mL}\right)$ scalable up to a working volume of $25 \mathrm{~L}$ are possible with $\mathrm{CHO}$ cells using perfusion culture intensification. ${ }^{[7,8]}$

These results indicate that high cell densities can be achieved in less time using perfusion culture in the seed train. Production runs incorporating intensified seed trains also have comparable growth kinetics and yields, as compared to the control seed train process at $50 \mathrm{~L}$ scale. By using an RM $50 \mathrm{~L}$ perfusion bioreactor to generate cell batches at a VCC of $50 \times 10^{6} / \mathrm{mL}$, scientists at Intas could potentially seed a $4000 \mathrm{~L}$ bioreactor with $25 \mathrm{~L}$ of this material to achieve a target inoculation VCC of $0.4 \times 10^{6} / \mathrm{mL}$.

\section{Conclusion}

The development and proof-of-concept studies detailed in this article have shown that using SU RM perfusion bioreactors to produce seed train material could potentially help Intas achieve process intensification up to $4000 \mathrm{~L}$ with fewer process transfer steps. This could measurably increase productivity while consuming fewer resources. Other positives include reducing the manufacturing footprint without changing the production bioreactor or feeding strategy, potentially delivering the products in Intas' biologics portfolio more cost-effectively.

\section{References}

[1] Reay D, Ramshaw C, Harvey A. A brief history of process intensification. In: Process intensification, 2nd edition. Butterworth-Heinemann, 2013, pp 1-20. https://www.elsevier.com/books/process-intensification/ reay/978-0-08-098304-2

[2] Yongky A, Xu J, Tian J, Oliveira C, Zhao J, McFarland K. Process intensification in fed-batch production bioreactors using non-perfusion seed cultures. $m A b s, 2019 ;$ 11(8): 1502-14. https://doi.org/10.1080/1942 0862.2019 .1652075

[3] Xu J, Xu X, Huang C, Angelo J, Oliveira CL, Xu M. Biomanufacturing evolution from conventional to intensified processes for productivity improvement: a case study. $m A b s, 2020 ; 12(1): 1770669$. https://doi.org/ 10.1080/19420862.2020.1770669

[4] Morrow KJ. Continual improvements advance continuous biomanufacturing. GEN, 2019. https://www.genengnews.com/topics/bioprocessing/ continual-improvements-advance-continuous-biomanufacturing/

[5] Pohlscheidt M, Jacobs M, Wolf S, Thiele J, Jockwer A, Gabelsberger J, Jenzsch M, Tebbe H, Burg J. Optimizing capacity utilization by large scale 3000 L perfusion in seed train bioreactors. Biotechnol Prog, 2013; 29(1): 222-229. https://doi.org/10.1002/btpr.1672

[6] Librizzi J. New flexsafe bag family: combining material science, film expertise and $\mathrm{QbD}$ for reliable and consistent cell growth. Bioprocess
Int, 2014. https://bioprocessintl.com/sponsored-content/new-flexsafe-bag-family-combining-material-science-film-expertise-qbd-reliable-consistent-cell-growth/

[7] Yang WC, Lu J, Kwiatkowski C, Yuan H, Kshirsager R, Ryll T, Huang YM. Perfusion seed cultures improve biopharmaceutical fed-batch production capacity and product quality. Biotechnol Prog, 2014; 30(3): 616-25. https://doi.org/10.1002/btpr.1884

[8] Zijlstra G. Integrated tools for upstream process intensification: part II. Manufacturing Chemist, 2019. https:// www.manufacturingchemist.com/news/article_page/ Integrated_tools_for_upstream_process_intensification_Part_II/157152 [9] Noack U et al. Single-use stirred tank reactor BIOSTAT CultiBag STR: characterization and applications. In: Single-use technology in biopharmaceutical manufacture. Eibl R, Eibl D eds, Wiley, Hoboken, New Jersey, 2010, pp 225-40. https://doi.org/10.1002/9781119477891

[10] Ruhl S, de Almeida N, Carpio M, Rupprecht J, Greller G, Matuszczyk JC. A rapid, low-risk approach process transfer of biologics from development to manufacturing scale. Bioprocess Int, 2020; 18(5): 44-51. https://bioprocessintl.com/sponsored-content/ biostat-str-bioreactors-a-rapid-low-risk-approach-process-transfer-of-biologics-from-development-to-manufacturing-scale/

\section{About the Authors}

Rajib Malla ${ }^{1}$, Dhaval D. Shah ${ }^{1}$, Chinmay Gajendragadkarr, Vijayalakshmi Vamanan ${ }^{1}$, Deepak Singh, PhD ${ }^{1}$, Suraj Gupta ${ }^{2}$, Deepak Vengovan ${ }^{2}$, Ravi Trivedi ${ }^{2}$, Henry Weichert ${ }^{3}$, Melisa Carpio ${ }^{4}$, and Krishna Chandran ${ }^{5}$

1. Intas Pharmaceuticals Ltd., Biopharma Division, Ahmedabad, Gujarat, India

2. Sartorius, Ahmedabad, Gujarat, India

3. Sartorius, Göttingen, Germany

4. Sartorius, San Francisco, California USA

5. Sartorius, Bangalore Urban, Karnataka, India

\section{Corresponding Authors:}

Deepak Vengovan (Deepak.Vengovan@Sartorius.com), Manager of Field Application Specialist CCT. Suraj Gupta (Surajkumar.Gupta@Sartorius.com), Field Application Specialist CCT.

Tel: +91.79 .6616 .8082$ 